\title{
Immune abnormalities and differential gene expression in the hippocampus and peripheral blood of patients with Alzheimer's disease
}

\author{
Xiaonan Wang ${ }^{1,2}$, Di Wang ${ }^{1,2}$, Fei Su ${ }^{3}$, Chunmei Li $^{1,2}$, Min Chen $^{1,2}$ \\ ${ }^{1}$ Department of Radiology, Beijing Hospital, National Center of Gerontology, Institute of Geriatric Medicine, Chinese Academy of Medical \\ Sciences, Beijing, China; ${ }^{2}$ Graduate School of Peking Union Medical College, Chinese Academy of Medical Sciences, Beijing, China; ${ }^{3}$ Clinical \\ Biobank, Beijing Hospital, National Center of Gerontology, Institute of Geriatric Medicine, Chinese Academy of Medical Sciences, Beijing, China \\ Contributions: (I) Conception and design: X Wang, C Li, M Chen; (II) Administrative support: C Li, M Chen; (III) Provision of study materials or \\ patients: X Wang; (IV) Collection and assembly of data: X Wang, D Wang; (V) Data analysis and interpretation: X Wang, F Su; (VI) Manuscript \\ writing: All authors; (VII) Final approval of manuscript: All authors. \\ Correspondence to: Chunmei Li; Min Chen. Department of Radiology, Beijing Hospital, National Center of Gerontology, Institute of Geriatric \\ Medicine, Chinese Academy of Medical Sciences, Beijing 100730, China. Email: bee9020@126.com; cjr.chenmin@vip.163.com.
}

Background: Despite decades of research, no precise mechanisms of Alzheimer's disease (AD) development have been elucidated. This study aimed to investigate novel diagnostic biomarkers in both peripheral blood cells and hippocampus tissue, and the pathogenesis of memory impairment in AD.

Methods: mRNA microarray data, including hippocampus samples (GSE1297 and GSE5281) and peripheral blood mononuclear cells (PBMCs) (GSE63060 and GSE63061), associated with AD were obtained from the Gene Expression Omnibus (GEO) database. Differentially expressed genes (DEGs) between $\mathrm{AD}$ and normal-aging samples were screened through a comprehensive analysis of multiple gene expression spectra after gene reannotation and batch normalization. The Gene Ontology (GO) and Kyoto Encyclopedia of Genes and Genomes (KEGG) pathways were used to analyze hub genes and to discover potential biomarkers related to AD. Protein-protein interaction (PPI) network maps were constructed to visualize the correlation between possible genes. The CIBERSORT algorithm was built to explore the patterns of PBMC infiltration to investigate the role of inflammation in the pathogenesis of $\mathrm{AD}$.

Results: The bioinformatics analysis indicated 1,261 DEGs in the hippocampal samples and 290 in PBMCs when comparing patients with $\mathrm{AD}$ with normal-aging individuals. We selected 28 genes co-expressed in the hippocampus and PBMCs. A functional analysis of differential genes revealed that they were primarily involved in neuronal death, immune response, and mitochondrial function. Further, immune cell infiltration patterns demonstrated that the levels of naive $\mathrm{CD}^{+}{ }^{+} \mathrm{T}$ cells, resting natural killer cells, $\mathrm{M} 0$ macrophages, and activated mast cells were higher in the peripheral blood of patients with $\mathrm{AD}$, while resting memory $\mathrm{CD}^{+} \mathrm{T}$ cells were significantly lower.

Conclusions: The key gene changes present in both the hippocampus and PBMCs highly suggest their utility as an AD biomarker. In addition, according to our present results, immune abnormalities may have an important role in $\mathrm{AD}$ pathophysiology. When patients display these peripheral blood immune abnormalities, they may be recognized as being at high risk of developing AD.

Keywords: Alzheimer's disease (AD); bioinformatics; Gene Expression Omnibus (GEO) database; gene expression; immune features

Submitted Sep 18, 2021. Accepted for publication Dec 06, 2021.

doi: 10.21037/atm-21-4974

View this article at: https://dx.doi.org/10.21037/atm-21-4974 


\section{Introduction}

Alzheimer's disease (AD) is a progressive neurodegenerative disease with primary clinical manifestations, including memory decline, cognitive impairment, and behavioral abnormalities (1). In 2018, AD was diagnosed in one individual every 3 seconds worldwide. Fifty million people are currently living with $\mathrm{AD}$, and this number will be three times as high by the year 2050. The global cost of AD care in the year 2018 was $\$ 1$ trillion, which is anticipated to rise to $\$ 2$ trillion by 2030 (2). Considering the high morbidity and economic burden of $\mathrm{AD}$, disentangling the etiology, and finding preventive measures are urgently needed.

Despite decades of research, no precise mechanisms of AD development have been elucidated. Hypotheses include the aggregation of amyloid- $\beta$ proteins into senile plaques (3), abnormal phosphorylation of $\tau$ protein to form neurofibrillary tangles (4), and early loss of synapses (5). Early detection methods were based on biomarkers expressed in the brain tissue and cerebrospinal fluid, which present challenges due to the highly invasive collection process and high cost. Therefore, obtaining peripheral blood biomarkers, which is non-invasive and cost-effective, is more applicable. Trying to find common genes differentially expressed in the peripheral blood cells and brain tissue is one of the most interesting aspects of investigating AD. Various diagnostic methods for AD have been studied, including cognitive tests (6), structural magnetic resonance imaging (7), electroencephalogram (8), ${ }^{18}$ F-fluorodeoxyglucose positron emission tomography (9), and cerebrospinal fluid biomarkers (10); however, each method has its own limitations. Therefore, we performed a bioinformatic analysis using human blood gene expression data from the Gene Expression Omnibus (GEO) database to explore more suitable detection methods.

In addition to the classical pathological hallmarks, neuroinflammation has recently been observed in $\mathrm{AD}$ (11). Neuroinflammation is not restricted to the microglia and astrocytes, which are the brain's resident immune cells, but includes strong interactions with peripheral immune cells including neutrophils (12), macrophages (13), and lymphocytes (14). Specifically, T-lymphocytes have been detected in human $\mathrm{AD}$ post-mortem specimens (15). In this study, we addressed the role of gene expression in AD and focused on the possibility that peripheral immune cells serve as hematological signatures that could aid in both diagnosis and management. We present the following article in accordance with the MDAR reporting checklist (available at https://atm. amegroups.com/article/view/10.21037/atm-21-4974/rc).

\section{Methods}

\section{Data acquisition}

The microarray datasets used in this study were selected from the GEO database of the National Center for Biotechnology Information (http://www.ncbi.nlm.gov/ geo). For the selection of expression profiling datasets, the following search terms were used: ["Alzheimer disease" [MeSH Terms] OR Alzheimer's disease [All Fields] AND \{"Homo sapiens" [porgn] AND "Expression profiling by array" [DataSet Type]\}. These search criteria allowed for the identification of different mRNA expression datasets, of which only those with $>20$ samples (total of control and $\mathrm{AD}$ samples) were selected for further computational analyses. Among them, two databases of hippocampus samples (GSE1297 and GSE5281) (16) and two databases of peripheral blood mononuclear cells (PBMCs) (GSE63060 and GSE63061) (17) were selected (Table 1). This research did not involve a human subject trial. Instead, the data came exclusively from the GEO. The study was conducted in accordance with the Declaration of Helsinki (as revised in 2013).

\section{Batch normalization and differential expression analysis}

The multiple dataset analyses were based on different instruments with different handlers or in different groups. First, we integrated GSE1297 and GSE5281 using R software with the "sva" package (version 4.0.3; R Foundation for Statistical Computing, Vienna, Austria). The combat approach was used to eliminate batch effects from different studies. Then, we used the "limma" package to identify differentially expressed genes (DEGs); value fold changes $(\mathrm{FC})$ with $\mid \log \mathrm{FCl}>2$ and adjusted $\mathrm{P}$ value $<0.05$ as cutoff values, false discovery rate $<0.05)$. The batch normalization of GSE63060 and GSE63061 used the same method. DEG pheatmaps were created using the trimmed mean of the $M$ value normalization factors.

\section{Enrichment analysis and protein-protein interaction (PPI)}

Gene Ontology (GO) and Kyoto Encyclopedia of Genes and Genomes (KEGG) pathway enrichment analyses of DEGs were used in the "clusterProfiler" package in R. GO information was screened with adjusted $\mathrm{P}$ value $<0.05$, 
Table 1 GEO microarray datasets

\begin{tabular}{lcccc}
\hline GEO ID & Platform & Normal-aging sample & AD sample & Resource \\
\hline GSE1297 & $\begin{array}{c}\text { GPL96 [HG-U133A] Affymetrix Human } \\
\text { Genome U133A Array }\end{array}$ & 9 & 22 & Hippocampus \\
GSE5281 & $\begin{array}{c}\text { GPL570 [HG-U133_Plus_2] Affymetrix } \\
\text { Human Genome U133 Plus 2.0 Array }\end{array}$ & 13 & 10 & Hippocampus \\
GSE63060 & $\begin{array}{c}\text { GPL6947 Illumina HumanHT-12 V3.0 } \\
\text { Expression BeadChip }\end{array}$ & 104 & 145 & Peripheral blood \\
GSE63061 & GPL10558 Illumina HumanHT-12 V4.0 \\
& Expression BeadChip & 134 & 139 & Peripheral blood \\
\hline
\end{tabular}

GEO, Gene Expression Omnibus; ID, identification; AD, Alzheimer's disease.

including the function of DEGs from three aspects: cellular component, molecular function (MF), and biological process (BP). The KEGG pathway terms with adjusted $\mathrm{P}$ value $<0.05$ were significantly enriched, depicting utilities of the biological system and high-level functions. STRING (version 11.0; https://string-db.org) is an online tool that provides visualization of PPI networks. Networks were performed based on gene expression, and the minimum required interaction score of 0.7 was considered statistically significant.

\section{Exploring immune infiltration}

CIBERSORT (https://cibersort.stanford.edu/) is a versatile computer algorithm that quantifies immunological characteristics based on gene expression signatures. We downloaded a gene signature matrix from CIBERSORT that included 22 immune cell types. These cells are a recategorization of 10 major cell types, including naive and memory $\mathrm{B}, 7$ kinds of $\mathrm{T}\left(\mathrm{CD} 8^{+} \mathrm{T}\right.$; activated memory, native, and resting memory $\mathrm{CD}^{+} \mathrm{T}$; and follicular helper, regulatory, and $\gamma \delta \mathrm{T}), 3$ kinds of macrophages (M0, M1, and M2), resting and activated dendritic, resting and activated mast, resting and activated natural killer, monocytes, eosinophils, neutrophils, and plasma cells. Then, we predicted the proportions of the 22 types of infiltrating immune cells in the $\mathrm{AD}$ and normal-aging samples. The number of permutations was set at 100 to improve the deconvolution algorithm's accuracy, and $\mathrm{P}<0.05$ was regarded as statistically significant.

\section{Statistical analysis}

All analyses were performed using R v.4.0.3 (https://www.
R-project.org). All data were expressed as means \pm standard deviations (SDs). The Wilcoxon rank-sum test was used for comparison between two groups. All tests were two-sided, and $\mathrm{P}<0.05$ was considered statistically significant.

\section{Results}

A total of 576 samples, comprising 54 hippocampal tissue expression samples and $522 \mathrm{PBMC}$ expression samples, were included in the current study. Among the hippocampus tissue expression subset, 9 normal-aging individuals and 22 patients with AD were obtained from GSE1297, and 13 normal-aging individuals and 10 patients with $\mathrm{AD}$ were obtained from GSE5281. For PBMCs, 104 normalaging individuals and 145 patients with $\mathrm{AD}$ were obtained from GSE1297, and 134 normal-aging individuals and 139 patients with $\mathrm{AD}$ were obtained from GSE5281 (Table 1). In the hippocampus tissue expression subset, the mean age of the 22 normal-aging individuals was $81.95 \pm 9.12$ years, of whom $7(31.82 \%)$ were female; the mean age for the 32 patients with $\mathrm{AD}$ was $83.63 \pm 8.19$ years, of whom 20 $(62.5 \%)$ were female. In the PBMC subset, the mean age at onset of the 238 normal-aging individuals in the was $74.02 \pm 6.32$ years, of whom $143(60.08 \%)$ were female; the mean age at onset for the 284 patients with $\mathrm{AD}$ was $76.62 \pm 6.73$ years, of whom $184(64.79 \%)$ were female (Table S1).

After batch normalization, the DEG analysis was performed using R. A total of 1,261 DEGs were found in the hippocampus tissue subset by matching GSE1297 and GSE5281, including 120 upregulated and 1,141 downregulated DEGs (Figure 1A). A total of 290 DEGs were found in the PBMC subset by matching GSE63060 and GSE63061, including 4 upregulated and 286 

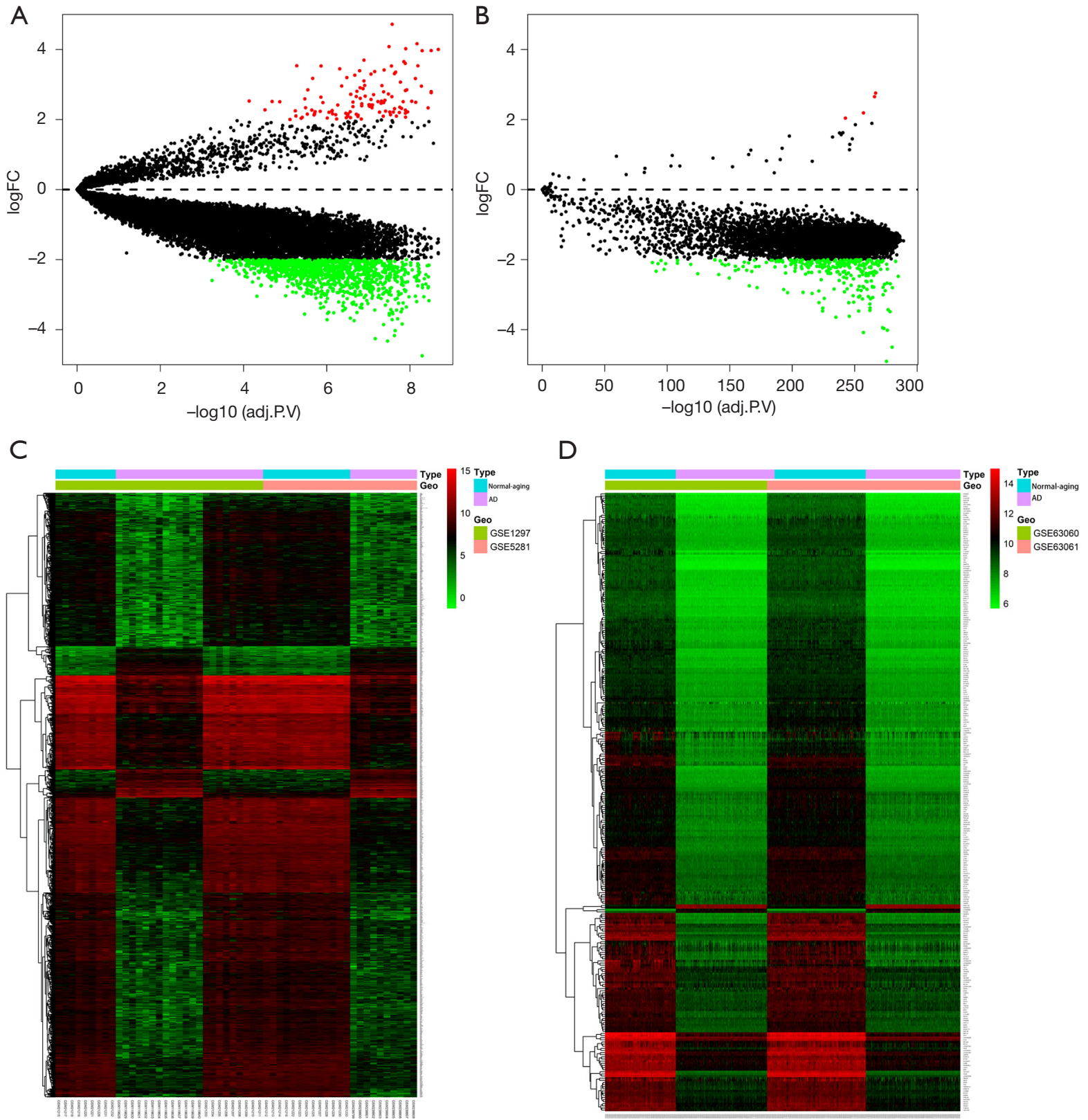

Figure 1 Analysis of differential expressed genes. Volcano plots of differential expressed genes in (A) hippocampus tissue and (B) PBMCs. The red dots represent the upregulated genes based on an adjusted $\mathrm{P}<0.05$ and $\log \mathrm{FC}>2$; the green dots represent the downregulated genes based on an adjusted $\mathrm{P}<0.05$ and $\log \mathrm{FC}<2$; and the black spots represent genes with no significant difference in expression. Heatmap of differential expressed genes in (C) hippocampus tissue and (D) PBMCs. The red color represents the upregulated genes; the green color represents the downregulated genes; and the black color represents genes without change. FC, fold changes; adj.P.V, adjusted P value; GEO, Gene Expression Omnibus; AD, Alzheimer's disease; PBMCs, peripheral blood mononuclear cells.

downregulated DEGs (Figure 1B). The DEGs identified in each subset are shown in Figure 1C,1D. The results showed 28 differential mRNA expressions among both hippocampus tissue and peripheral blood sets (Figure 2, Table S2).
To explore the potential biological functions and signaling pathways of DEGs in patients with $\mathrm{AD}$, we further enriched and analyzed the two subsets. GO enrichment analysis is useful for uncovering the significantly integrated 


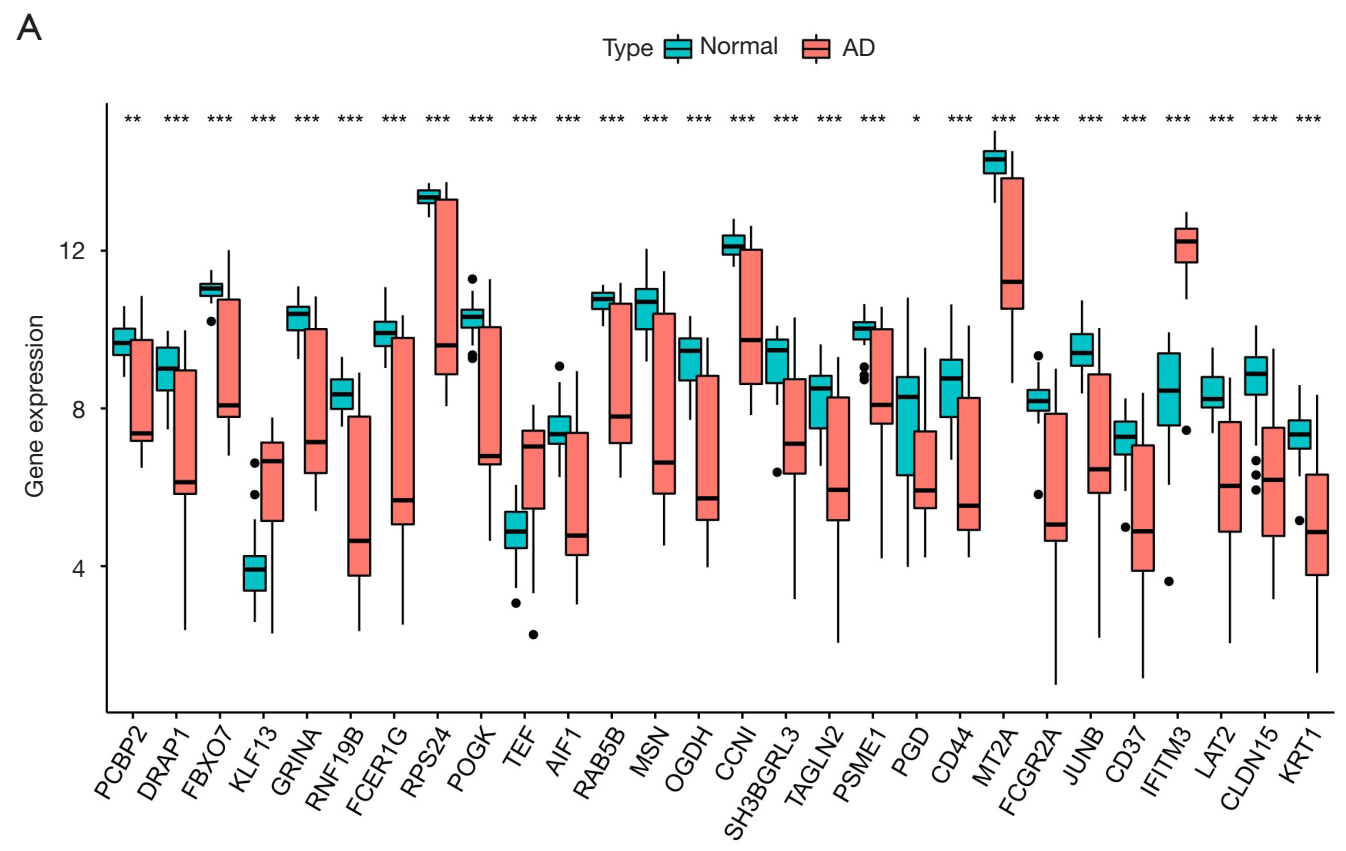

B Type 追 Normal 追 AD

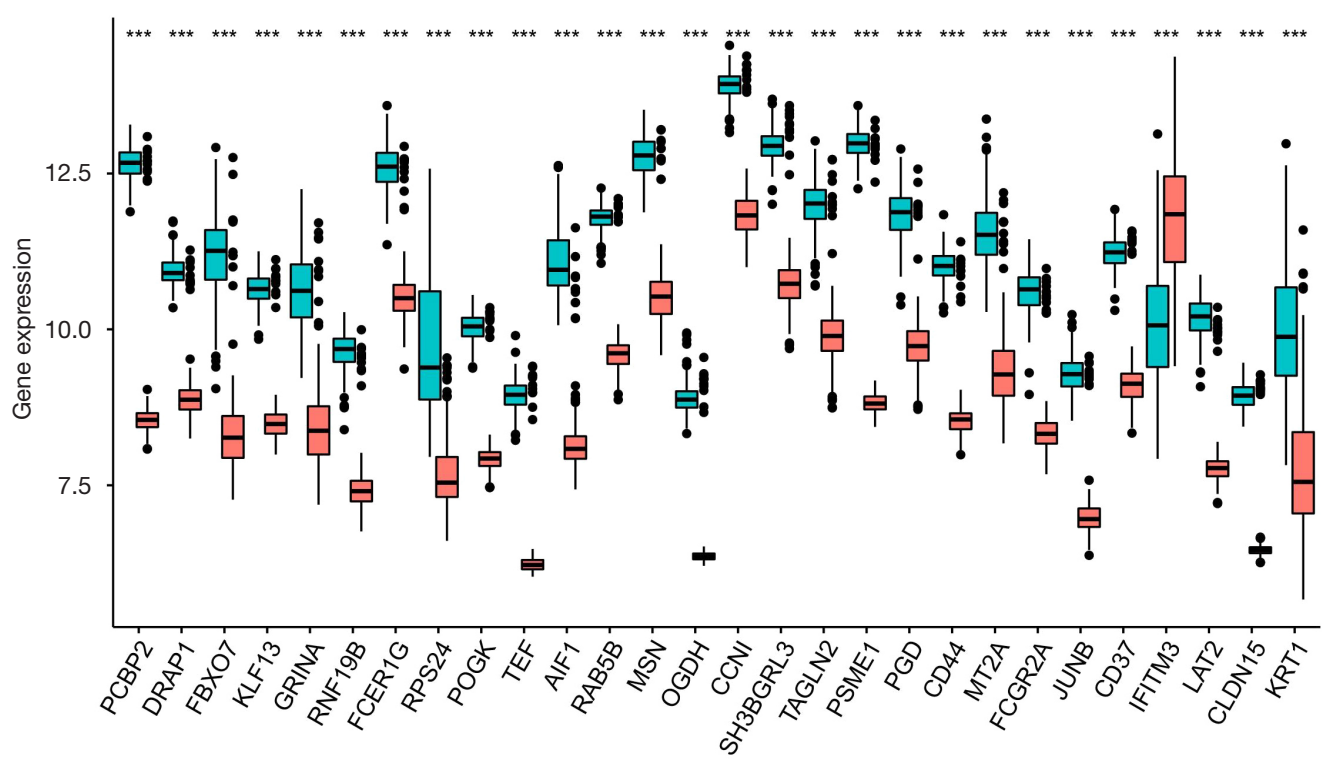

Figure 2 Differential expression of the 28 common genes between $\mathrm{AD}$ and normal tissues in the (A) hippocampus tissue and (B) PBMCs. *, $\mathrm{P}<0.05 ;{ }^{* *}, \mathrm{P}<0.01 ;{ }^{* * *}, \mathrm{P}<0.001$. AD, Alzheimer's disease; PBMCs, peripheral blood mononuclear cells.

DEGs. Results of the three most significant BP terms, including biological process, cellular component, and MF, in hippocampus tissue are shown in Figure 3. As for BP terms, neutrophil activation involved in immune response was the most significant term, followed by gliogenesis, neutrophil degranulation, glial cell differentiation, and glial cell development. Regarding cellular components (CC), the DEGs were enriched mainly in the collagen-containing extracellular matrix, external side of plasma membrane, vesicle lumen, secretory granule lumen, and cytoplasmic 


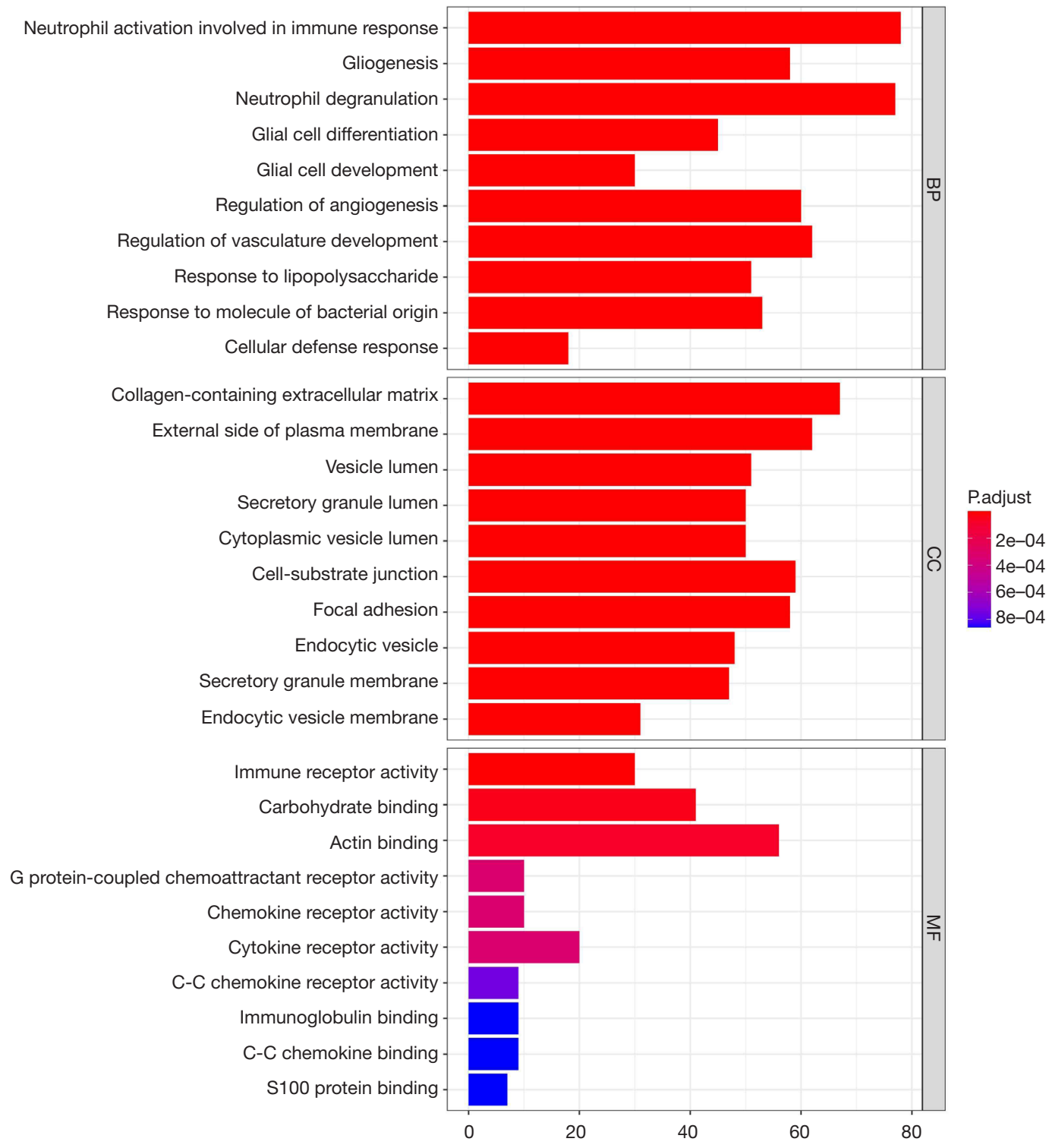

Figure 3 Enrichment of hippocampus differential expressed genes are identified in the ontology categories. BP, biological process; CC, cellular components; MF, molecular function.

vesicle lumen. Besides the enrichment levels of MF, the BPs were primarily associated with immune receptor activity, carbohydrate binding, and actin binding. In PBMCs (Figure 4), the top three BP terms were neutrophil degranulation, neutrophil activation involved in immune response, and $\mathrm{T}$ cell activation. As for cellular component terms, the DEGs were enriched mainly in the mitochondrial matrix, cytoplasmic vesicle lumen, and vesicle lumen. Regarding MF, the DEGs were enriched mainly in protein serine/threonine kinase activity and ubiquitin-like protein ligase binding. KEGG analysis showed the possible signaling pathways of DEGs. We also analyzed the KEGG pathways with an adjusted $\mathrm{P}$ value $<0.05$ that were enriched in hippocampal tissue and PBMC subsets. The KEGG pathways are shown in Figure S1. Although the biological function enrichment of the hippocampus was not identical to PBMCs after screening, there was a close association between the death of neurons, immune response, and mitochondrial function in the hippocampus and PBMCs.

In addition to gene set enrichment analysis, we 


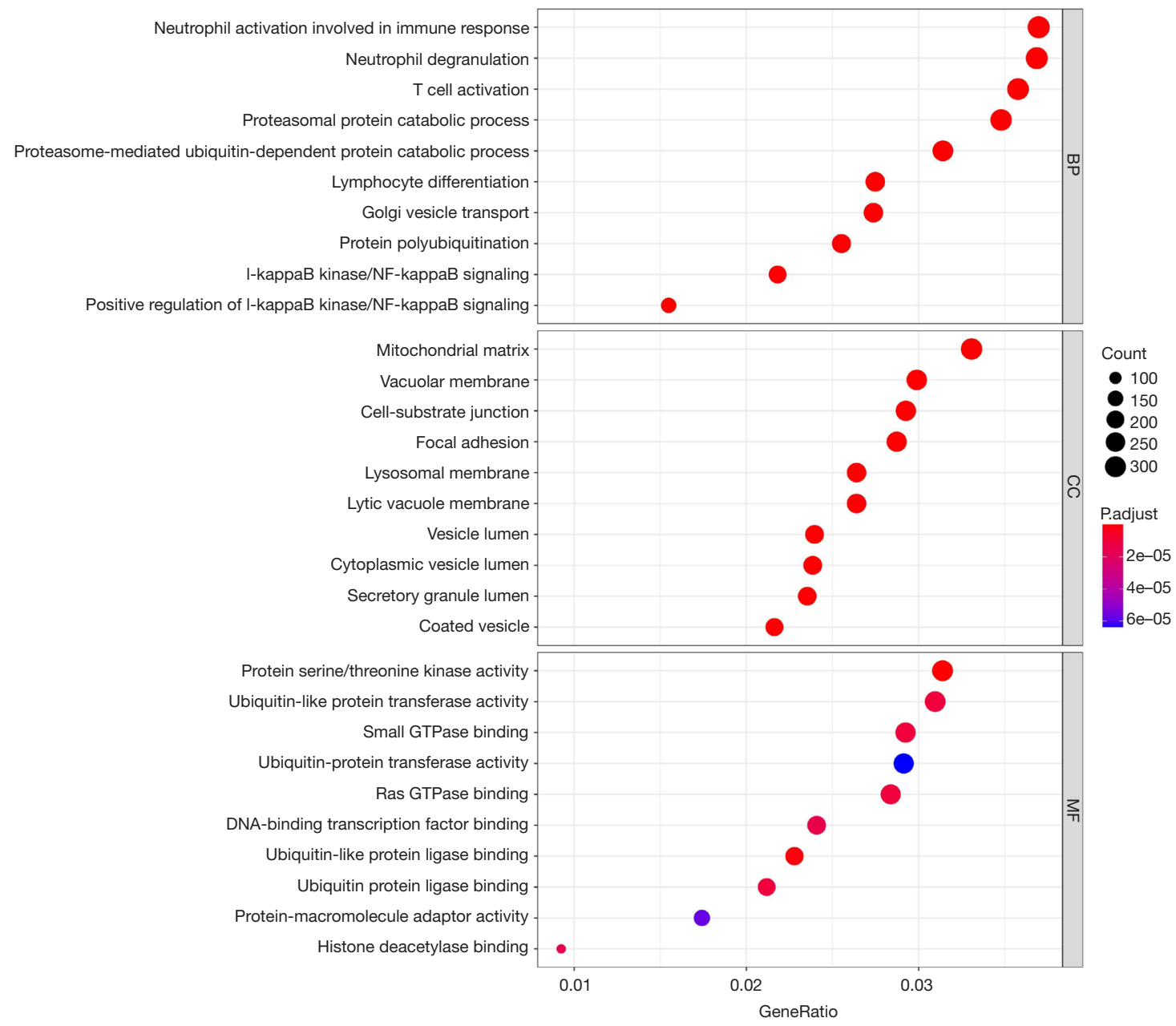

Figure 4 Enrichment of PBMCs differential expressed genes are identified in the ontology categories. BP, biological process; CC, cellular components; MF, molecular function; PBMCs, peripheral blood mononuclear cells.

performed PPI network analysis through the hub DEGs using the STRING interactome database. We performed a zero-order interaction analysis to simplify the network to a more manageable size. As a result, we detected a PPI network, including 668 nodes and 3,121 edges in the hippocampal tissue subset and 142 nodes and 389 edges in the PBMC subset (Figure 5). Figure S2 shows the top 40 hub genes, ranked according to the link in the PPI network (the number of nodes they connect to). According to the enrichment analyses, patients with AD demonstrated close associations with the immune response. Therefore, we further explored the immune cell infiltration patterns of PBMCs to investigate the role of inflammation in the pathogenesis of AD. As shown in Figure 6, fractions of some immune cells varied significantly between normalaging individuals and patients with $\mathrm{AD}$. In all, four immune cells in the patients with $\mathrm{AD}$ group showed significantly higher infiltration levels, including naive $\mathrm{CD}^{+}{ }^{+} \mathrm{T}$ cells, resting natural killer cells, M0 macrophages, and activated mast cells, while resting memory $\mathrm{CD}^{+} \mathrm{T}$ cells were significantly lower in the patients with $\mathrm{AD}$ group. Although the proportions of the six immune cells were significantly different between the two groups (including native B cells, follicular helper T cells, $\gamma \delta \mathrm{T}$ cells, resting dendritic cells, resting mast cells, and eosinophils) at a false detection rate $<0.05$, they were significantly lower in all samples. Importantly, it was difficult to identify if they truly matched the patients with $\mathrm{AD}$ group. 
A

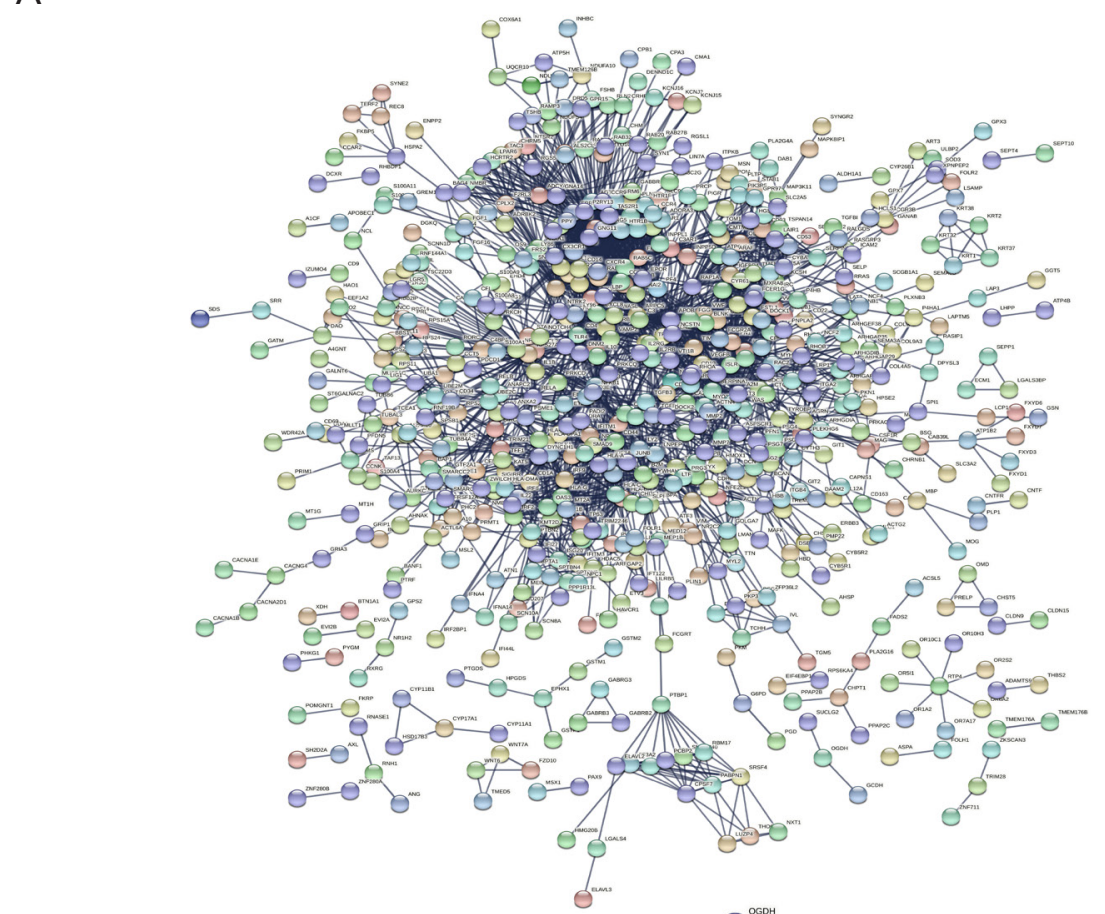

B

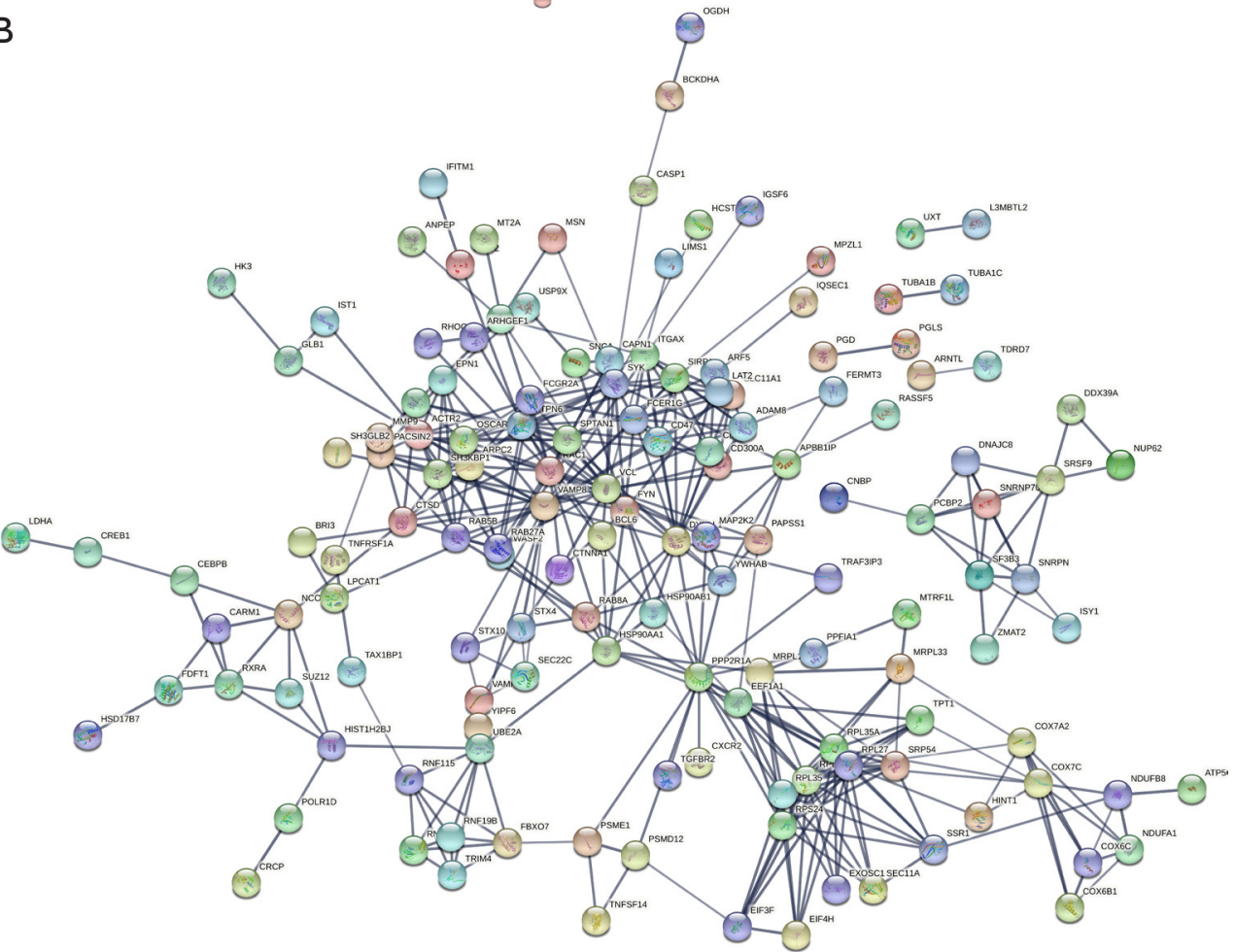

Figure 5 PPI network. PPI network and modules of intersecting differential expressed genes of (A) hippocampus samples and (B) PBMCs. PPI, protein-protein interaction; PBMCs, peripheral blood mononuclear cells. 


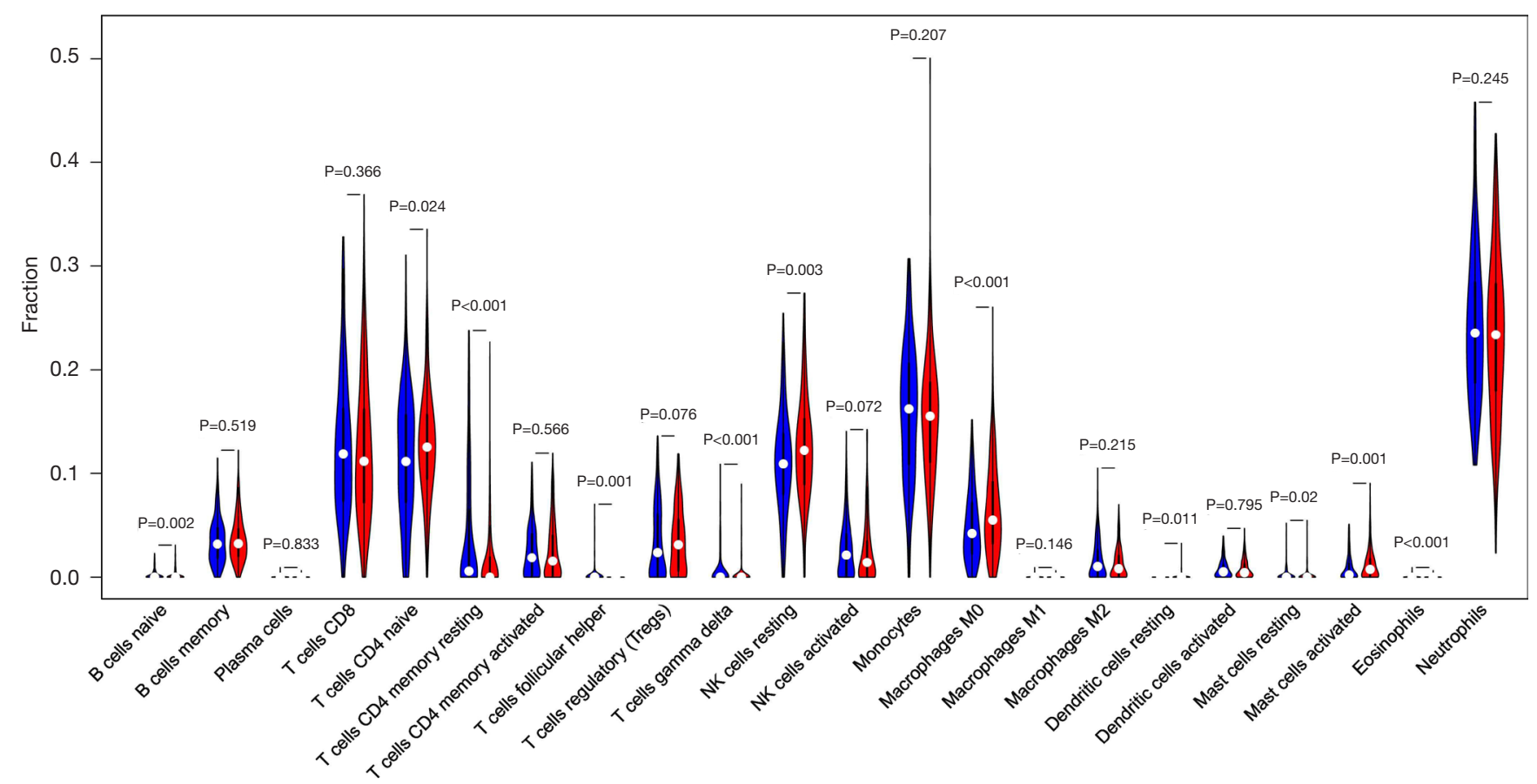

Figure 6 Comparison of immune cell infiltration between normal aging individuals samples and patients with $\mathrm{AD}$. The blue represents the fractions of immune cells in normal-aging individuals, and the red represents that in patients with AD. AD, Alzheimer's disease.

\section{Discussion}

With the development of microarrays and high-throughput sequencing technologies, a bioinformatic analysis of $\mathrm{AD}$ has been recently investigated; however, most of the current research is based on invasive methods and a single array, leading to poor acceptance and a lack of multiple cohorts for joint research. In our current study, we used both the hippocampus and PBMCs from $\mathrm{AD}$ and normalaging samples to identify blood biomarkers that predicted brain tissue biomarkers to diagnose $\mathrm{AD}$ without brain biopsy or a cerebrospinal fluid analysis. By using GO and KEGG analyses, we found that DEGs from the AD and normal-aging samples were related to neuronal death, mitochondrial function, and most importantly, immune response. We further explored the immune cell infiltration patterns of PBMCs to investigate the role of inflammation in the pathogenesis of $\mathrm{AD}$.

Various prior methods have shown that peripheral blood gene expression can be used for the diagnosis of multiple brain disorders despite the effects of the blood-brain barrier $(18,19)$. Moradi et al. (20) used a linear discriminant analysis method to study blood gene expression profiles that shows peripheral blood genes have a potential application value to classify healthy and $\mathrm{AD}$; however the study did not mention the association between peripheral blood genes and brain tissue genes. Voyle et al. (21) applied a pathwaybased interpretation of gene expression to diagnosis $\mathrm{AD}$, but the model only performed similarly to a model based on demographic information. Our study used a novel approach by extracting data from the hippocampus and PBMCs of patients with $\mathrm{AD}$ and normal-aging samples, and 28 genes were obtained in the intersection between the two groups of DEGs, to link peripheral blood and brain tissue.

$R A B S B$ is among the important GTPases of the RAB protein family $(22,23)$. We found that $R A B 5 B$ was significantly downregulated in the hippocampus in GSE1297 and GSE5281, and the expression of RABSB was also downregulated in PBMCs in GSE63060 and GSE63061. N-methyl-D-aspartate (NMDA) receptors have an important role in nerve cell death associated with activation of surface receptors sensitive to glutamate (24). Previous studies showed that NMDA receptors are internalized by a clathrin-dependent mechanism $(25,26)$. A decrease in $R A B 5 B$ could lead to abnormal internalization of NMDA receptors and induce excitatory toxicity mediated by the receptor $(27,28)$. 
Considering the dysregulation of the NMDA pathway, $R A B 5 B$ may be a potential target in $\mathrm{AD}$.

It has been argued that the pathogenesis of $\mathrm{AD}$ is associated with abnormal mitochondria that produce excessive neuronal oxidative stress in the surrounding cytoplasm, causing damage to susceptible neurons (29-31). $P C B P 2$, the RPS gene family, and the $R A B$ gene family (32-34) have been implicated in mitochondrial dysfunction and oxidative damage in the pathogenesis of $\mathrm{AD}$ in past research, which is consistent with our present results. Consistent with our study, Lunnon et al. (35) also validated mitochondrial dysfunction and inflammatory changes occurring very early in $\mathrm{AD}$. These results will provide a reference for further investigation of early treatment and detection methods.

In addition, through the PPI network, we found that some other hub genes are closely related to AD occurrence. RPS27A, the gene with the largest number of connecting nodes in hippocampal tissue, has not only been shown to be a bridge gene for the progression of $\mathrm{AD}$ pathology, but has been widely studied in multiple neurodegenerative diseases (36). $A P O B$ has 52 node genes and has been widely used in studies of AD. For example, Di Paolo et al. (37) revealed $A P O B$ as a new link between cholesterol and $\mathrm{AD}$ and may underlie $\mathrm{AD}$ pathogenesis common to both late-onset $\mathrm{AD}$ and early-onset $\mathrm{AD}$. $V A M P 8$ was considered the most core gene in peripheral blood consistent with the results of a previous neuronal models study showing that VAMP 8 could increase tau secretion (38). Neuroinflammation mediated by microglia and astrocytes, as well as by peripheral immune cells, has been described as an important contributor to $\mathrm{AD}$ $(39,40) . C D 44$, an inflammation-related gene identified as a binding partner in cell adhesion and migration of immune cells $(41,42)$, may contribute to AD pathology. In our current study, expression of CD44 was significantly downregulated in the hippocampus following changes in PBMCs. Consistent with our results, Uberti et al. (43) reported that $C D 44$ was abnormally expressed in lymphocytes of patients with $\mathrm{AD}$ compared with healthy participants, which may be driving the immune response into infected tissues, including the central nervous system. Previous studies have also shown that the expression patterns of the CD44 gene family are different between patients with $\mathrm{AD}$ and matched non-AD controls in postmortem hippocampal samples (44). Some CD44 splice variants were localized to neuritic plaques and astrocytes, while some were localized in neuroblastoma cells and primary neurons. In addition, CD44 levels were increased in the frontal cortex of patients with severe AD who died with an antemortem clinical diagnosis compared with that of those with mild cognitive impairment (45). Considering the significant changes in $C D 44$ expression and role of $C D 44$ protein, $C D 44$ may be a therapeutic target in $\mathrm{AD}$.

Current research suggests that there are strong inflammatory reactions mediated by resident brain cells and through peripheral immune cells, which infiltrate the brain at various stages of disease progression (40). As the immune environment in the peripheral blood changes, brain tissue metabolism, signaling, and BPs also change. We believe that adverse indicators in PBMCs are a signal of early pathological changes in $\mathrm{AD}$. If long-term immune system abnormalities are found in elderly people, especially in $\mathrm{CD}^{+} \mathrm{T}$ cells, natural killer cells, macrophages, and mast cells, early cognitive screening and intervention for $\mathrm{AD}$ are warranted; however, our current study did not determine abnormal cut-off values, and large-sample data comparing normal-aging individuals and patients with $\mathrm{AD}$ are necessary for future studies. Although immune abnormalities do not necessarily lead to $\mathrm{AD}$, we speculate that elderly people with long-term immune system abnormalities have a much higher risk of $\mathrm{AD}$ than the general older adult population. Treatment of early inflammatory reactions may delay the onset and progression of $\mathrm{AD}$.

According to this study, key genes are potential biomarkers to predict and to diagnose $\mathrm{AD}$. Thus, $\mathrm{AD}$ could be diagnosed by testing the patient's peripheral blood, without brain tissue biopsy or cerebrospinal fluid testing. These genes suggest that $\mathrm{AD}$ onset may be associated with the immune pathway; therefore, we must further explore the effects of immunity on $\mathrm{AD}$. We recommend routine blood testing for older adults annually. If peripheral blood immune cell abnormalities are found over time, patients should have cognitive examinations or early interventions. This study may provide noninvasive methods for early identification of $\mathrm{AD}$ or possible targets for future $\mathrm{AD}$ treatment.

\section{Conclusions}

In conclusion, our current study found that the expression of several key genes changes in both the hippocampus and PBMCs of patients with $\mathrm{AD}$, strongly suggesting their utility as disease biomarkers. In addition, immune abnormalities may have an important role in $\mathrm{AD}$ pathophysiology. When patients exhibit long-term peripheral blood immune 
abnormalities, they may be recognized as being at high risk for $\mathrm{AD}$, leading to closer observed medical treatment.

\section{Acknowledgments}

We would like to thank Editage (https://www.editage.cn) for English language editing.

Funding: This study was supported by the National Natural Science Foundation of China (grant number: 81771826).

\section{Footnote}

Reporting Checklist: The authors have completed the MDAR reporting checklist. Available at https://atm.amegroups. com/article/view/10.21037/atm-21-4974/rc

Conflicts of Interest: All authors have completed the ICMJE uniform disclosure form (available at https://atm. amegroups.com/article/view/10.21037/atm-21-4974/coif). The authors have no conflicts of interest to declare.

Ethical Statement: The authors are accountable for all aspects of the work in ensuring that questions related to the accuracy or integrity of any part of the work are appropriately investigated and resolved. This research did not involve a human subject trial. Instead, the data came exclusively from the GEO. The study was conducted in accordance with the Declaration of Helsinki (as revised in 2013).

Open Access Statement: This is an Open Access article distributed in accordance with the Creative Commons Attribution-NonCommercial-NoDerivs 4.0 International License (CC BY-NC-ND 4.0), which permits the noncommercial replication and distribution of the article with the strict proviso that no changes or edits are made and the original work is properly cited (including links to both the formal publication through the relevant DOI and the license). See: https://creativecommons.org/licenses/by-nc-nd/4.0/.

\section{References}

1. Isaev NK, Stelmashook EV, Genrikhs EE, et al. Alzheimer's Disease: An Exacerbation of Senile Phenoptosis. Biochemistry (Mosc) 2015;80:1578-81.

2. Alzheimer's Disease International. World Alzheimer Report 2018: The state of the art of dementia research: New frontiers 2018. Available online: https://www.alzint. org/resource/world-alzheimer-report-2018/

3. Selkoe DJ. Toward a comprehensive theory for Alzheimer's disease. Hypothesis: Alzheimer's disease is caused by the cerebral accumulation and cytotoxicity of amyloid betaprotein. Ann N Y Acad Sci 2000;924:17-25.

4. Atwood CS, Bowen RL. A Unified Hypothesis of Earlyand Late-Onset Alzheimer's Disease Pathogenesis. J Alzheimers Dis 2015;47:33-47.

5. Gouras GK, Tsai J, Naslund J, et al. Intraneuronal Abeta 42 accumulation in human brain. Am J Pathol 2000;156:15-20.

6. Pinto TCC, Machado L, Bulgacov TM, et al. Is the Montreal Cognitive Assessment (MoCA) screening superior to the Mini-Mental State Examination (MMSE) in the detection of mild cognitive impairment (MCI) and Alzheimer's Disease (AD) in the elderly? Int Psychogeriatr 2019;31:491-504.

7. Hojjati SH, Ebrahimzadeh A, Babajani-Feremi A. Identification of the Early Stage of Alzheimer's Disease Using Structural MRI and Resting-State fMRI. Front Neurol 2019;10:904.

8. Gaubert S, Raimondo F, Houot M, et al. EEG evidence of compensatory mechanisms in preclinical Alzheimer's disease. Brain 2019;142:2096-112.

9. Yan Y, Somer E, Grau V. Classification of amyloid PET images using novel features for early diagnosis of Alzheimer's disease and mild cognitive impairment conversion. Nucl Med Commun 2019;40:242-8.

10. Gupta Y, Lama RK, Kwon GR, et al. Prediction and Classification of Alzheimer's Disease Based on Combined Features From Apolipoprotein-E Genotype, Cerebrospinal Fluid, MR, and FDG-PET Imaging Biomarkers. Front Comput Neurosci 2019;13:72.

11. Heneka MT, Carson MJ, El Khoury J, et al. Neuroinflammation in Alzheimer's disease. Lancet Neurol 2015;14:388-405.

12. Zenaro E, Pietronigro E, Della Bianca V, et al. Neutrophils promote Alzheimer's disease-like pathology and cognitive decline via LFA-1 integrin. Nat Med 2015;21:880-6.

13. Prokop S, Miller KR, Drost N, et al. Impact of peripheral myeloid cells on amyloid- $\beta$ pathology in Alzheimer's disease-like mice. J Exp Med 2015;212:1811-8.

14. Baruch K, Yoles E. Commentary: Chronic PD-1 Checkpoint Blockade Does Not Affect Cognition or Promote Tau Clearance in a Tauopathy Mouse Model. Front Aging Neurosci 2020;12:135.

15. Merlini M, Kirabali T, Kulic L, et al. Extravascular CD3 + T Cells in Brains of Alzheimer Disease Patients 
Correlate with Tau but Not with Amyloid Pathology: An Immunohistochemical Study. Neurodegener Dis 2018;18:49-56.

16. Ma G, Liu M, Du K, et al. Differential Expression of mRNAs in the Brain Tissues of Patients with Alzheimer's Disease Based on GEO Expression Profile and Its Clinical Significance. Biomed Res Int 2019;2019:8179145.

17. Sood S, Gallagher IJ, Lunnon K, et al. A novel multi-tissue RNA diagnostic of healthy ageing relates to cognitive health status. Genome Biol 2015;16:185.

18. Lewczuk P, Riederer P, O'Bryant SE, et al. Cerebrospinal fluid and blood biomarkers for neurodegenerative dementias: An update of the Consensus of the Task Force on Biological Markers in Psychiatry of the World Federation of Societies of Biological Psychiatry. World J Biol Psychiatry 2018;19:244-328.

19. Goldsmith DR, Rapaport MH, Miller BJ. A metaanalysis of blood cytokine network alterations in psychiatric patients: comparisons between schizophrenia, bipolar disorder and depression. Mol Psychiatry 2016;21:1696-709.

20. Moradi E, Marttinen M, Häkkinen T, et al. Supervised pathway analysis of blood gene expression profiles in Alzheimer's disease. Neurobiol Aging 2019;84:98-108.

21. Voyle N, Keohane A, Newhouse S, et al. A Pathway Based Classification Method for Analyzing Gene Expression for Alzheimer's Disease Diagnosis. J Alzheimers Dis 2016;49:659-69.

22. Bock JB, Matern HT, Peden AA, et al. A genomic perspective on membrane compartment organization. Nature 2001;409:839-41.

23. Somsel Rodman J, Wandinger-Ness A. Rab GTPases coordinate endocytosis. J Cell Sci 2000;113 Pt 2:183-92.

24. Horak M, Holubova K, Nepovimova E, et al. The pharmacology of tacrine at N-methyl-d-aspartate receptors. Prog Neuropsychopharmacol Biol Psychiatry 2017;75:54-62.

25. Wang R, Reddy PH. Role of Glutamate and NMDA Receptors in Alzheimer's Disease. J Alzheimers Dis 2017;57:1041-8.

26. Hallschmid M. Intranasal Insulin for Alzheimer's Disease. CNS Drugs 2021;35:21-37.

27. Man HY, Lin JW, Ju WH, et al. Regulation of AMPA receptor-mediated synaptic transmission by clathrindependent receptor internalization. Neuron 2000;25:649-62.

28. Baskys A, Bayazitov I, Zhu E, et al. Rabmediated endocytosis: linking neurodegeneration, neuroprotection, and synaptic plasticity? Ann N Y Acad Sci 2007;1122:313-29.

29. Wang WW, Han R, He HJ, et al. Delineating the Role of Mitophagy Inducers for Alzheimer Disease Patients. Aging Dis 2021;12:852-67.

30. Kerr JS, Adriaanse BA, Greig NH, et al. Mitophagy and Alzheimer's Disease: Cellular and Molecular Mechanisms. Trends Neurosci 2017;40:151-66.

31. Yin F, Sancheti H, Patil I, et al. Energy metabolism and inflammation in brain aging and Alzheimer's disease. Free Radic Biol Med 2016;100:108-22.

32. Ryu MS, Zhang D, Protchenko O, et al. PCBP1 and NCOA4 regulate erythroid iron storage and heme biosynthesis. J Clin Invest 2017;127:1786-97.

33. Garcia-Esparcia P, Sideris-Lampretsas G, HernandezOrtega $\mathrm{K}$, et al. Altered mechanisms of protein synthesis in frontal cortex in Alzheimer disease and a mouse model. Am J Neurodegener Dis 2017;6:15-25.

34. Wong YC, Ysselstein D, Krainc D. Mitochondrialysosome contacts regulate mitochondrial fission via RAB7 GTP hydrolysis. Nature 2018;554:382-6.

35. Lunnon K, Ibrahim Z, Proitsi P, et al. Mitochondrial dysfunction and immune activation are detectable in early Alzheimer's disease blood. J Alzheimers Dis 2012;30:685-710.

36. Tao Y, Han Y, Yu L, et al. The Predicted Key Molecules, Functions, and Pathways That Bridge Mild Cognitive Impairment (MCI) and Alzheimer's Disease (AD). Front Neurol 2020;11:233.

37. Di Paolo G, Kim TW. Linking lipids to Alzheimer's disease: cholesterol and beyond. Nat Rev Neurosci 2011;12:284-96. Erratum in: Nat Rev Neurosci 2011;12:484.

38. Pilliod J, Desjardins A, Pernègre C, et al. Clearance of intracellular tau protein from neuronal cells via VAMP8induced secretion. J Biol Chem 2020;295:17827-41.

39. Marlatt M, Lee HG, Perry G, et al. Sources and mechanisms of cytoplasmic oxidative damage in Alzheimer's disease. Acta Neurobiol Exp (Wars) 2004;64:81-7.

40. Olsen I, Singhrao SK. Inflammasome Involvement in Alzheimer's Disease. J Alzheimers Dis 2016;54:45-53.

41. Johnson P, Ruffell B. CD44 and its role in inflammation and inflammatory diseases. Inflamm Allergy Drug Targets 2009;8:208-20.

42. Tan ZS, Beiser AS, Vasan RS, et al. Inflammatory markers and the risk of Alzheimer disease: the Framingham Study. 
Neurology 2007;68:1902-8.

43. Uberti D, Cenini G, Bonini SA, et al. Increased CD44 gene expression in lymphocytes derived from Alzheimer disease patients. Neurodegener Dis 2010;7:143-7.

44. Pinner E, Gruper Y, Ben Zimra M, et al. CD44 Splice Variants as Potential Players in Alzheimer's Disease

Cite this article as: Wang $\mathrm{X}$, Wang $\mathrm{D}$, Su F, Li C, Chen M. Immune abnormalities and differential gene expression in the hippocampus and peripheral blood of patients with Alzheimer's disease. Ann Transl Med 2022;10(2):29. doi: 10.21037/atm-214974
Pathology. J Alzheimers Dis 2017;58:1137-49.

45. Moreno-Rodriguez M, Perez SE, Nadeem M, et al.

Frontal cortex chitinase and pentraxin neuroinflammatory alterations during the progression of Alzheimer's disease. J Neuroinflammation 2020;17:58. 
Supplementary

Table S1 Aggregate demographics

\begin{tabular}{lcccccc}
\hline & \multicolumn{3}{c}{ Hippocampus tissue subset } & & \multicolumn{2}{c}{ PBMCs subset } \\
\cline { 2 - 5 } \cline { 5 - 6 } Clinical factors & $\begin{array}{c}\text { Normal-aging } \\
\text { sample }\end{array}$ & AD sample & adj.P.V & & $\begin{array}{c}\text { Normal-aging } \\
\text { sample }\end{array}$ & AD sample \\
\hline Age (year) & $81.95 \pm 9.12$ & $83.63 \pm 8.19$ & 0.75 & $74.02 \pm 6.32$ & $74.62 \pm 6.73$ \\
Gender (F/M) & $7 / 15$ & $20 / 12$ & 0.11 & $143 / 95$ & $184 / 100$ \\
\hline
\end{tabular}

PBMCs, peripheral blood mononuclear cells; AD, Alzheimer's disease; adj.P.V, adjusted P value; F/M, female/male.

Table S2 The intersection of differentially expressed mRNAs both in the hippocampal tissue and PBMCs subsets

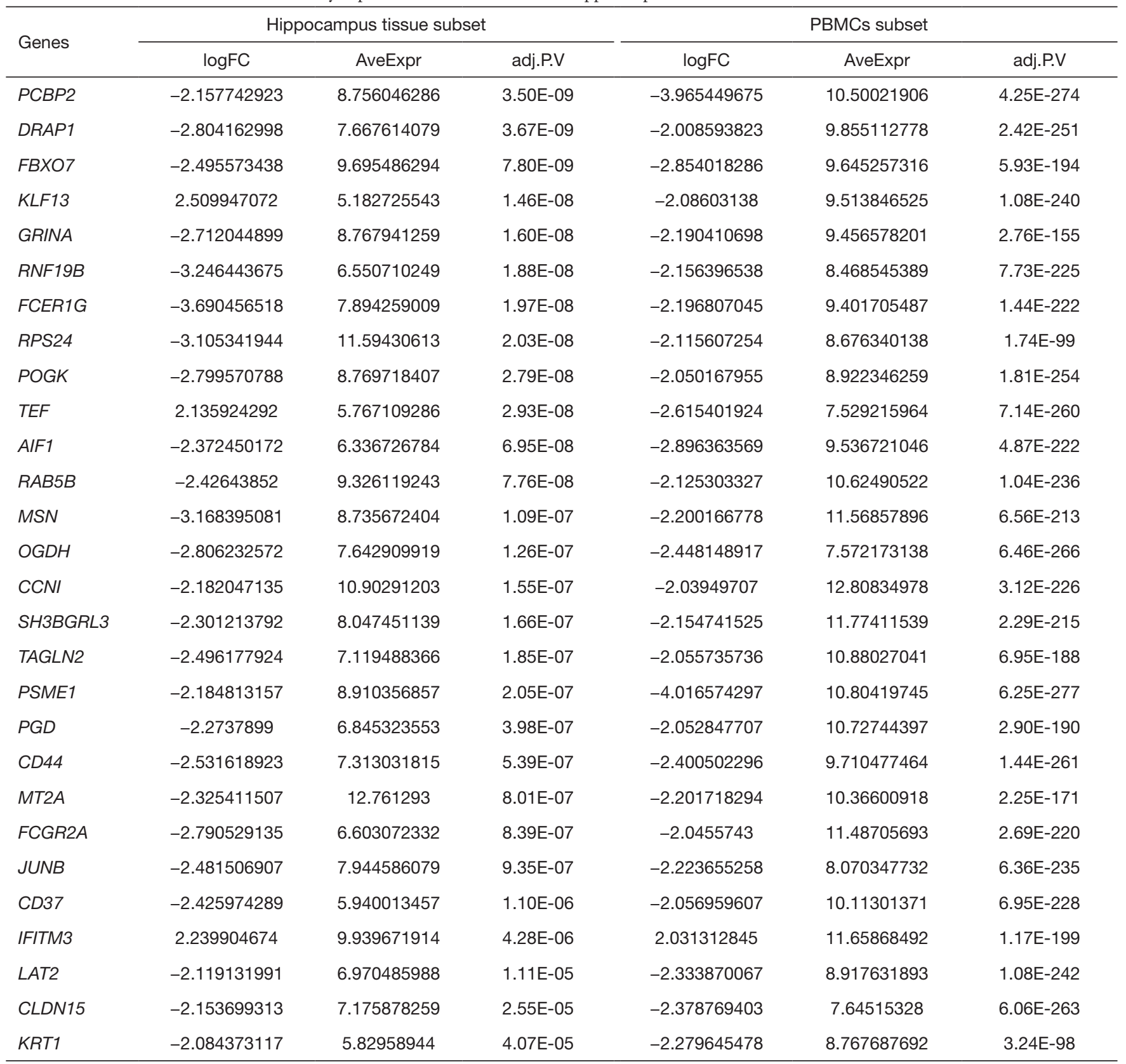

PBMCs, peripheral blood mononuclear cells; FC, fold changes; AveExpr, average expression; adj.P.V, adjusted P value.

(C) Annals of Translational Medicine. All rights reserved. 
A

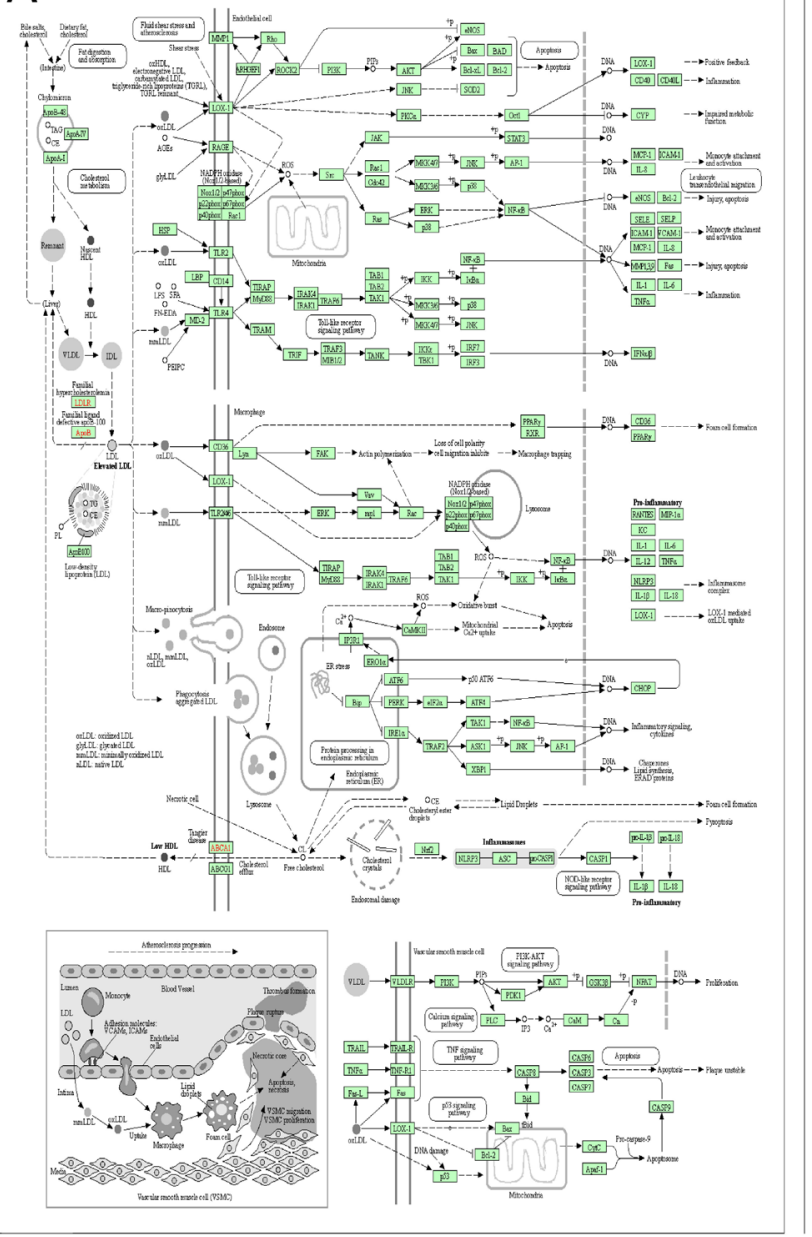

B

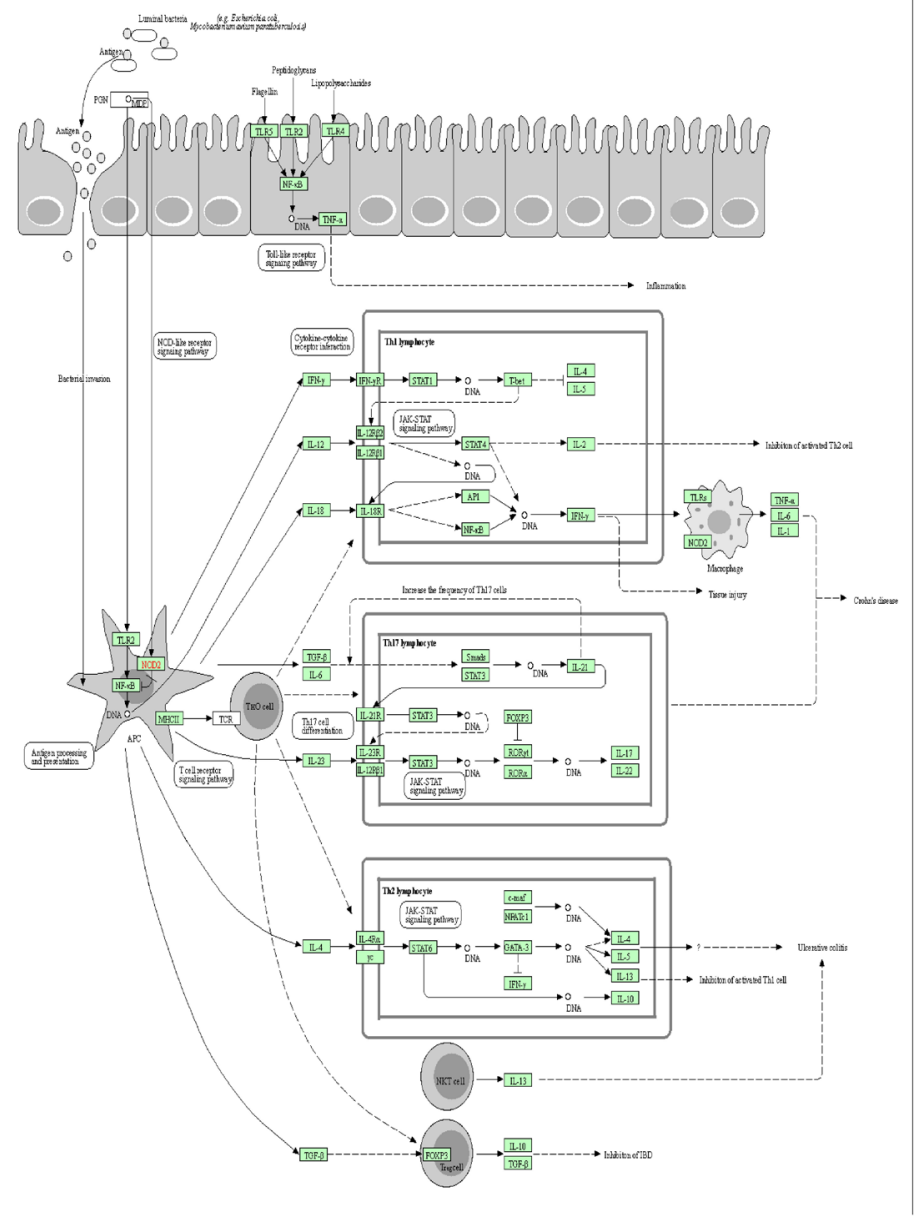

Figure S1 KEGG pathways in the hippocampal tissue and peripheral blood mononuclear cells subsets. KEGG, Kyoto Encyclopedia of Genes and Genomes. 
A

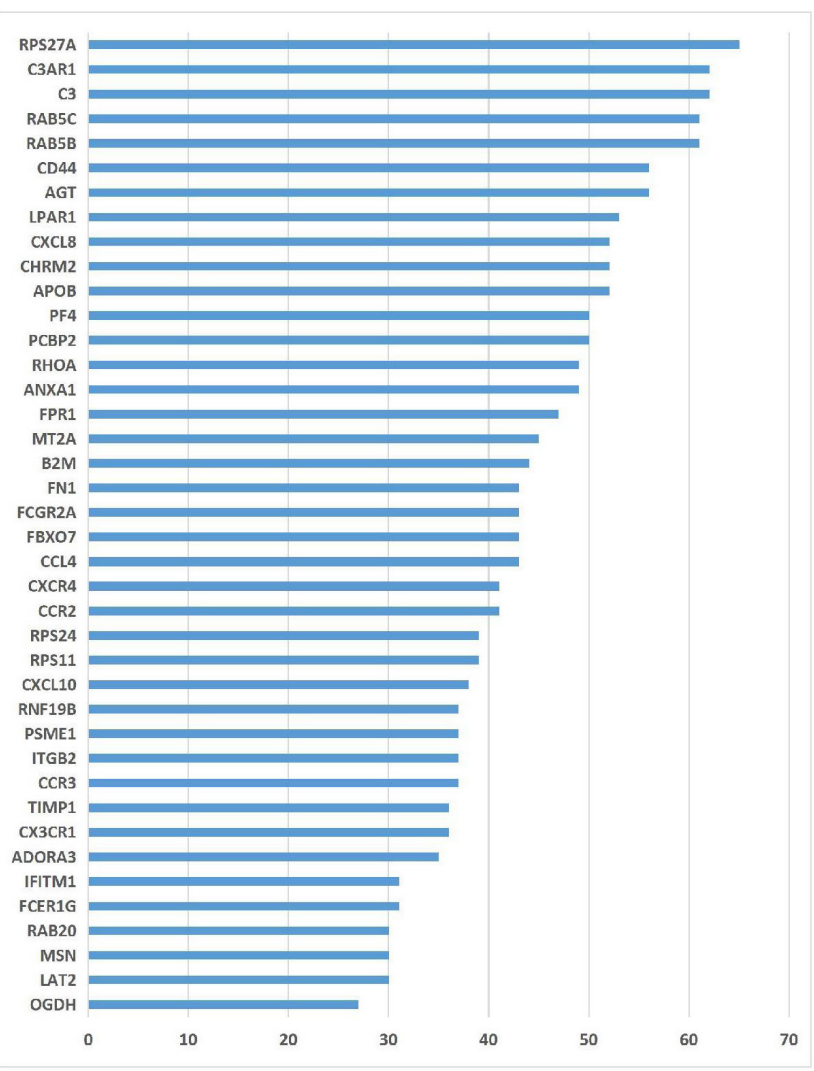

B

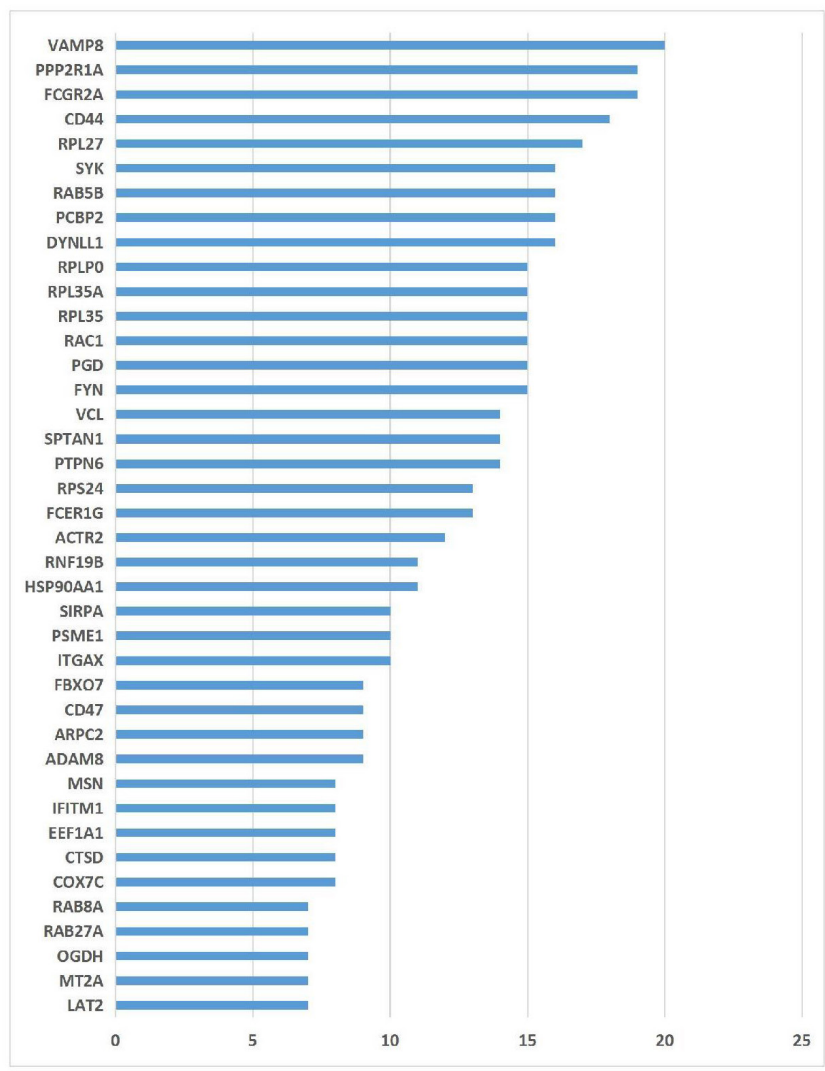

Figure S2 Bar graphs showing the top 40 hub genes, ranked according to their connectedness in the PPI network (the number of nodes they are connected with) in (A) hippocampus samples and (B) peripheral blood mononuclear cells. PPI, protein-protein interaction. 